\title{
DO GÊNERO DE AVALIAÇÃO À AVALIAÇÃO DO GÊNERO
}

Valeska Zanello ${ }^{1}$

RESUMO: O presente artigo teve como escopo analisar a experiência da autora na criação de uma nova metodologia de avaliação no curso de filosofia da linguagem, tendo em vista a alta freqüência de cópias de trabalho da web, por parte dos alunos. No entanto, a busca de um novo gênero de avaliação acabou por enveredar, inesperadamente, numa perspectiva onde a própria avaliação foi questionada como política de gênero.

\section{Introdução}

O presente artigo é um relato de minha própria experiência, como professora universitária dos cursos de psicologia, filosofia e pedagogia. Tenho observado, nos últimos anos, uma recorrência crescente entre os alunos do ensino superior no mau uso da Internet, quando se trata de realizar trabalhos de final de curso (matérias e não apenas TCC). Isto é, espera-se que tais trabalhos sejam criativos e passem por uma elaboração pessoal dos temas abordados durante o semestre, mas os mesmos acabam por serem muitas vezes copiados de maneira integral e literal da web.

De um lado, percebo um certo olhar "branco" por parte de muitos professores que, sem saber muito bem como agir, acabam por tornar invisível o fenômeno, desqualificando, ainda que não seja seu intento, o próprio processo educativo.

Por outro lado, alguns professores têm evitado a solicitação de trabalhos de fim de semestre, o que de alguma maneira inviabiliza que o aluno possa fazer um percurso

\footnotetext{
${ }^{1}$ Psicóloga, bacharel em filosofia, psicopedagoga, doutora em psicologia pela Universidade de Brasília (com doutorado sanduíche no Instituto Superior de Filosofia da Université Catholique de Louvain, na Bélgica). É professora do IESB/Brasília.
} 
pessoal, por exemplo, na escolha de um tema de seu interesse, dentro da margem geral do programa da matéria.

Frente à angústia que venho sentindo face a esta situação, impôs-se para mim a necessidade de pensar alternativas de avaliação que não a mera prova tradicional e nem o trabalho de tema livre. Isso me fez enveredar por caminhos inesperados que me levaram, por fim, a questionar as próprias habilidades que estavam sendo avaliadas e suas possíveis implicações no que tange às relações de gênero.

A necessidade de alternativas

Foi a partir do segundo semestre de 2005, depois de ter detectado cópias de textos da Internet nos trabalhos finais do curso de filosofia da linguagem que estava ministrando, que me ocorreu a idéia da realização de um trabalho diferente, alternativo. Pude detectá-las através da busca no Google. Para resolver esse impasse, que para mim não se tratava apenas de um caso de necessidade de punição do aluno, por exemplo, dando-lhe um zero, resolvi solicitar-lhes a realização de um álbum. Neste álbum deveriam estar presentes em resumos, bem sintéticos, as principais idéias de todas as teorias de linguagem estudadas durante o semestre e, o mais importante, muitas ilustrações da vida prática, cotidiana, que exemplificassem essas teorias. Em outras palavras, os alunos deveriam não apenas ler os textos, mas resumi-los. Não apenas resumi-los, mas compreendê-los, a ponto de serem capazes de fazer a ponte entre a teoria e a vida cotidiana. O resultado foi surpreendente! Não apenas pela riqueza dos exemplos dados, mas pela variabilidade dos modos pessoais de execução do álbum. Entrevistando, pessoalmente, cada aluno, acerca de seu álbum, pude ver claramente o desenvolvimento e o envolvimento pessoal com as idéias abordadas e retratadas em seus trabalhos.

Abaixo, podemos ver uma parte de um desses álbuns, ao exemplificar, em primeiro lugar, algumas idéias do Tractatus e, depois, a teoria dos jogos de linguagem de Wittgenstein. De acordo com esse filósofo, em um segundo momento de seu pensamento, o sentido da palavra é seu uso, o que a aluna retratou com os diversos usos da palavra "pedir". Alguns desses exemplos seriam: pedir segredo, pedir em casamento, pedir perdão, pedir um abraço... 


\section{PROPOSIÇÃO}

A PROPOSIČ̃̃O É COMO UMA FLECHA APONTADA PARA O MUNDO MARCADA PELA BIPOLARIDADE (VERDADEIRO OU FALSO). A PROPOSIÇÃO CRIA UMA FIGURAÇÃO E SE ESSA FIGURAÇÃO APONTADA PARA O MUNDO ATINGE O ALVO ELA É VERDADEIRA. EXISTE UM ESPAÇO LÓGICO FIGURATIVO QUE DEVE SEMPRE SER VERDADEIRO.

EXEMPLO: O SOL É AMARELO; V (X) OU FALSO ( ).?
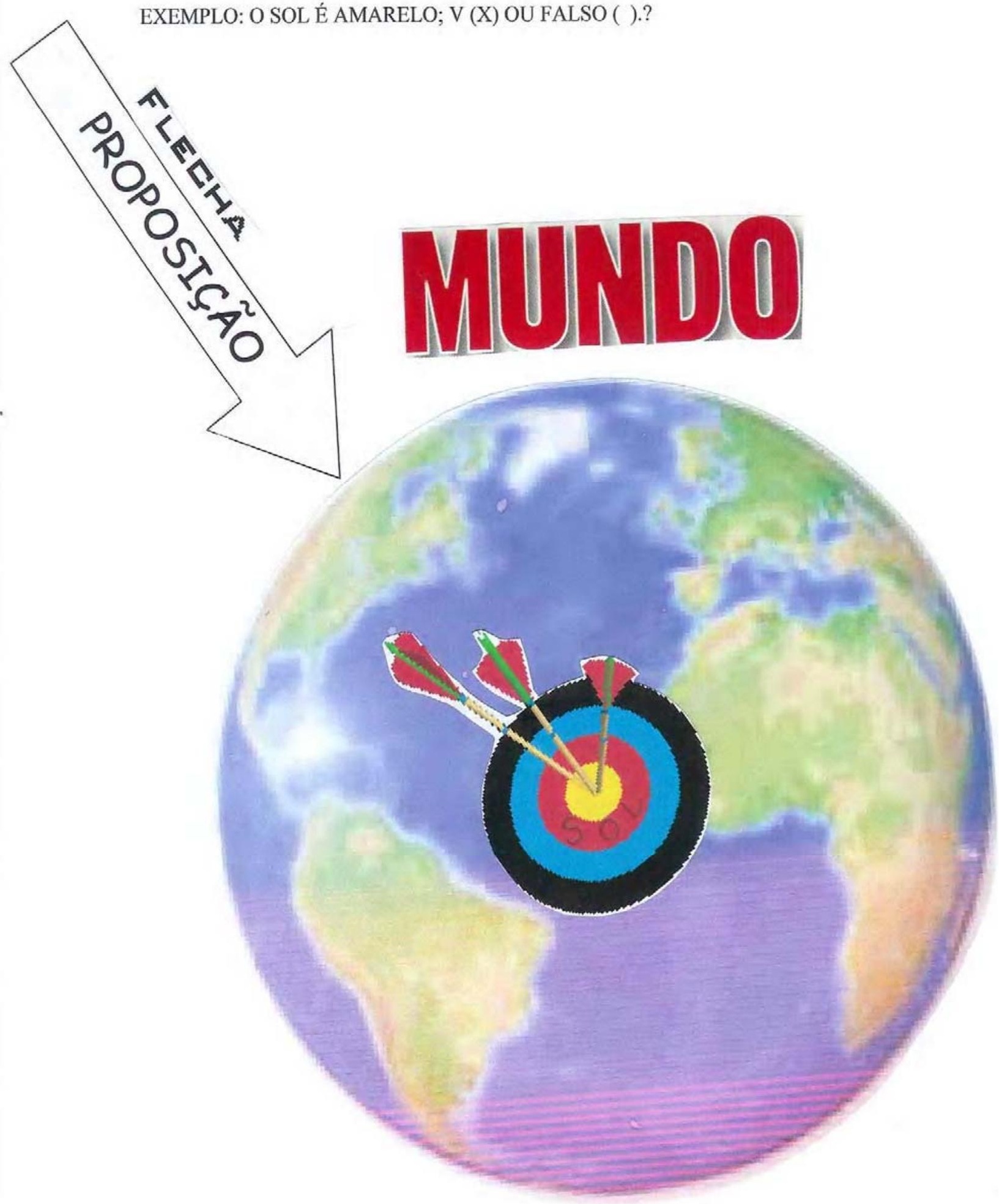
WITTGENSTEIN ABANDONA O TRACTATUS POR CONTER ELEMENTOS METAFÍSICOS, OU SEJA, AS PROPOSICÕES DO TRATACTUS APLICADAS AOS AFORISMOS NÃO FAZEM SENTIDO. O TRATACTUS NÃO FAZ SENTIDO PARA RESOLVER OS PROBLEMAS DE LIMPEZA DA LINGUAGEM.

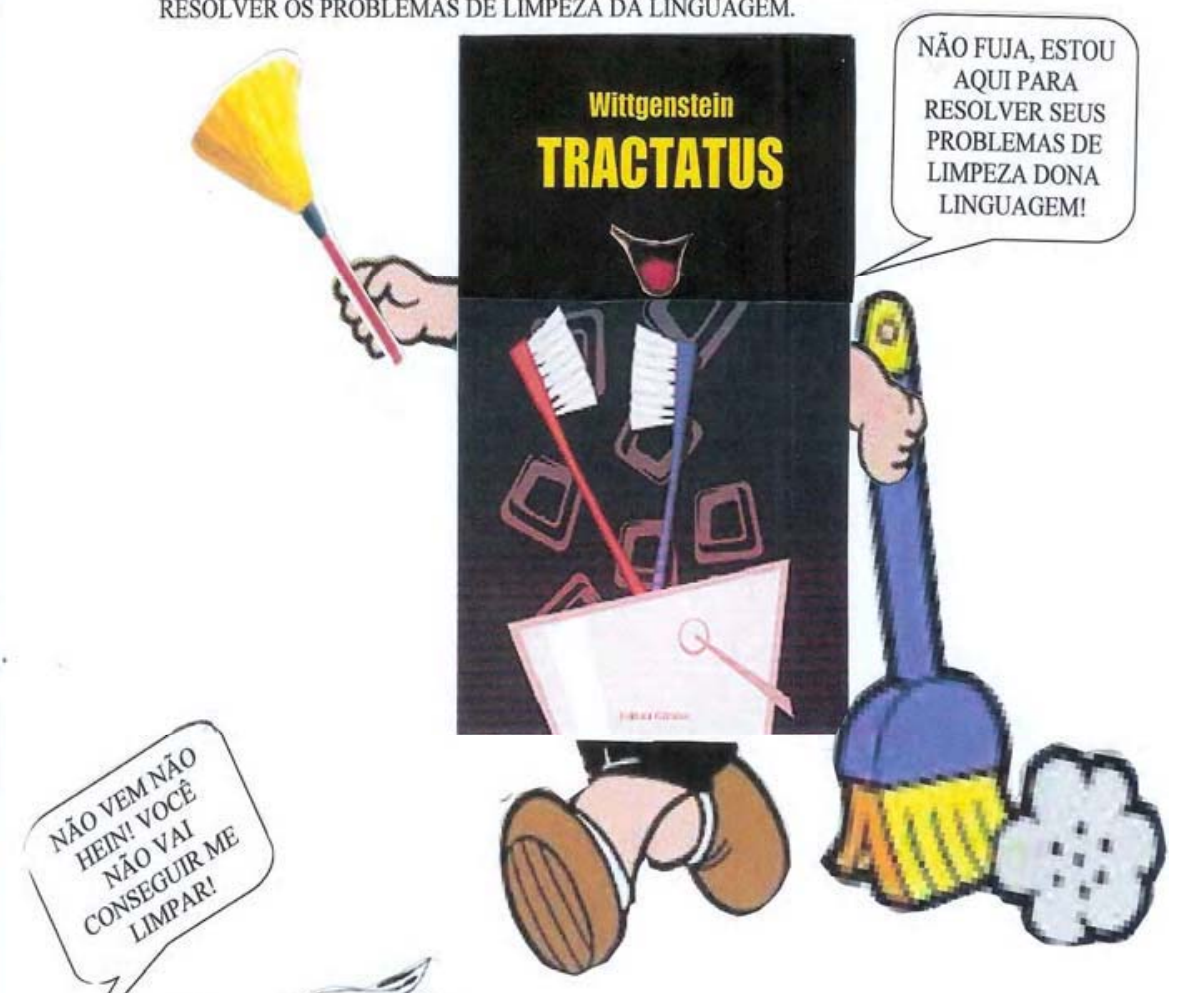


- A MESMA PALAVRA PODE TER USO E SENTIDO DIFERENTE; EXEMPLO: "PEDIR"

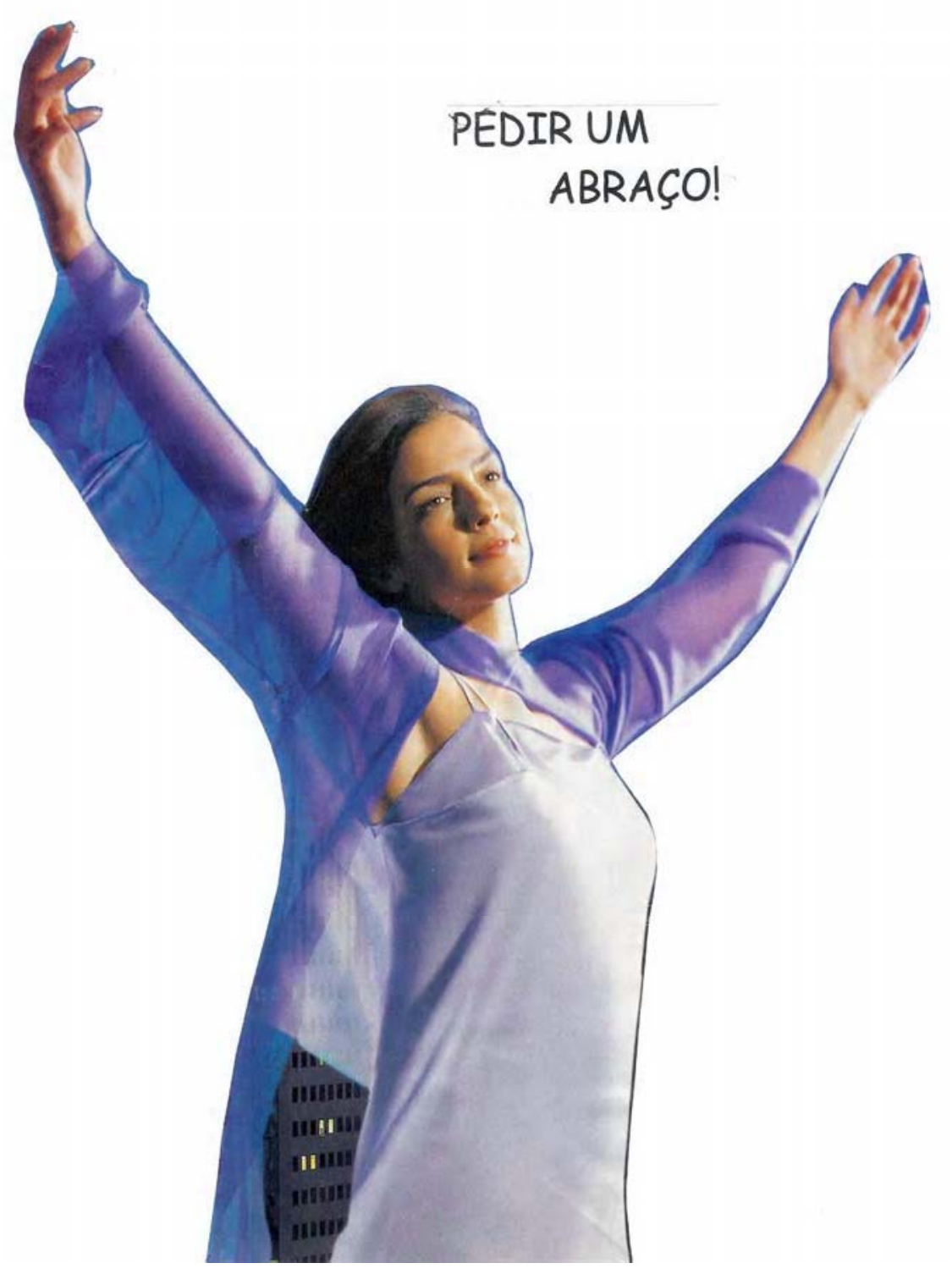




\section{PEDIR}

\section{SEGREDO!}

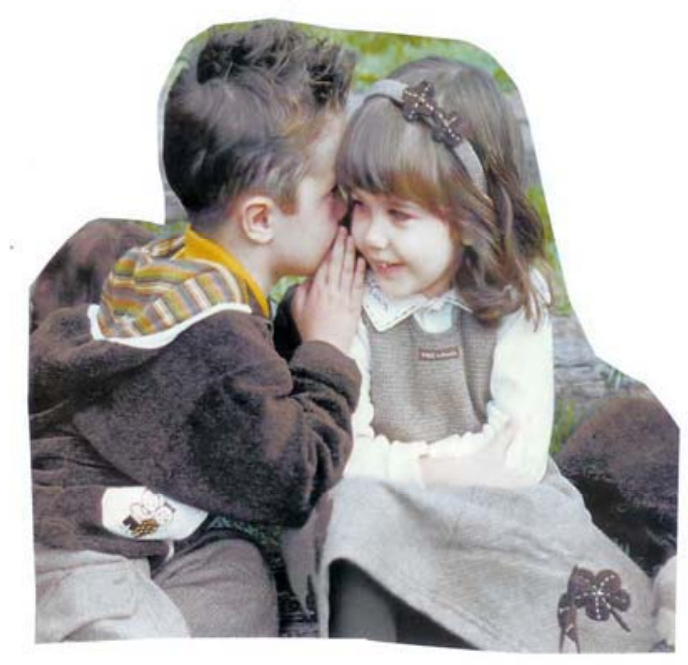

\section{PEDIR EM}

CASAMENTO!

PEDIR

PERDÃO!
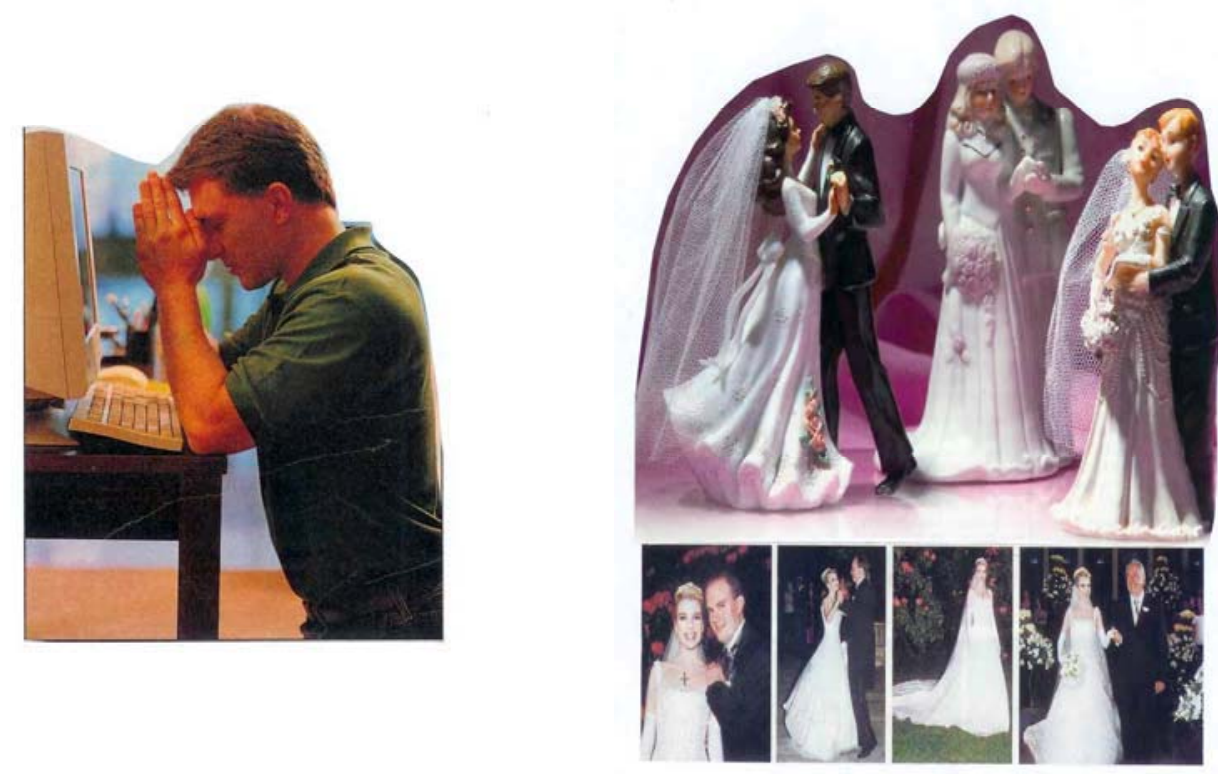

A reclamação acerca do excesso de trabalho para se fazer o álbum, no começo do semestre, foi generalizada, mas a mesma foi se diluindo na própria execução da 
tarefa e o resultado final foi apresentado, de modo geral, com grande orgulho e satisfação. O próprio excesso de trabalho parece ter sido elaborado com humor, como podemos ver na situação a seguir, na qual uma aluna, Ana Cláudia Barbosa, criou o seguinte exemplo de ato de fala diretivo, para retratar a idéia de que fazemos coisas com as palavras:

\section{COMANDAR, E AGIR SEGUNDO COMANDOS}

(DAR E RECEBER ORDEM)

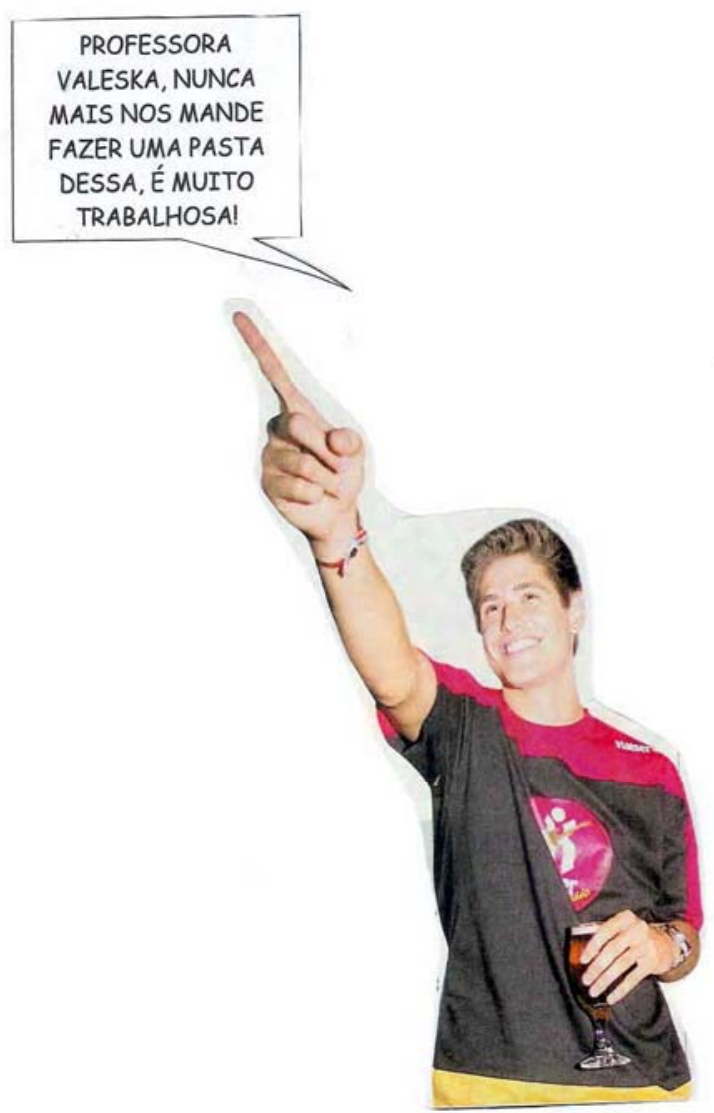

Além dos álbuns feitos no papel, os alunos acabaram por desenvolver, por conta própria, um DVD do curso de filosofia da linguagem, com imagens, sons e exemplos que retratavam tudo aquilo que havíamos estudado e discutido no curso. Como o resultado dos álbuns e do DVD foi surpreendente, resolvi realizar, no fim do semestre, uma espécie de exposição com os álbuns dos alunos e algumas performances deles 
(cartazes, exposição do DVD, etc.) para toda a faculdade. Tal exposição constituiu-se como uma oportunidade de os alunos sentirem seus trabalhos valorizados e reconhecidos, o que se mostrou como mais uma fonte produtora de motivação e engajamento pessoal deles. Nesse sentido, não foram pouco freqüentes os elogios dos outros alunos, que não os de nossa classe, e frases do tipo "Aprendi demais com o seu álbum e com seus exemplos!".

Um fator interessante que, apesar de não ter sido fonte nem objeto de minha preocupação inicialmente, saltou aos meus olhos, diz respeito à diferenciação de gênero nesse tipo de avaliação. As meninas se destacaram tanto na parte estética do álbum, quanto na capacidade de realizar a ponte entre as teorias e os exemplos da vida cotidiana. Como estudiosa e interessada no tema das relações de gênero, não posso deixar de fazer menção a esse fato, pois ele não me passou desapercebido. Na verdade, ele me fez questionar se os tipos tradicionais de avaliação também não são repletos de vieses de relações de gênero, isto é, se não solicitam habilidades de gênero socialmente construídas desde a mais tenra infância (de alguns sujeitos em detrimento de outros). Em outras palavras, especificamente no curso de filosofia (histórica e genericamente relacionado a homens), a metodologia de avaliação pode reforçar crenças misóginas, naturalizantes, quando de fato, as habilidades solicitadas são aquelas reforçadas pela cultura nos homens. Isto me fez lembrar as palavras de MACCOLL (apud CERLETTI \& KOHAN, 1999, p. 28): "Ser uma mulher fazendo filosofia é, em certo sentido, ser uma desajustada. Não no sentido de vestir roupas excêntricas ou de colorir os cabelos, mas no sentido de que, como mulheres, não nos ajustamos bem ao guarda-chuva dos filósofos, ou a seus sapatos, ou ao que vocês quiserem pensar dele. É claro, somos, sem dúvida, muito boas filósofas e podemos usar o guarda-chuva do filósofo tão bem quanto qualquer um, mas, embora ninguém tenha notado, não nos sentimos confortáveis com isso. A razão é que, assim como nos assumimos, temos que deixar de ser mulheres, temos que nos ajustar ao hábito. Este fato de perder o gênero não é um requisito para o filósofo homem que veste o uniforme filosófico com desenvoltura porque, na verdade, foi desenhado para ele (...). Uma forma de expor o problema geral da filosofia com as mulheres é que ela está profunda e exaustivamente imbuída de uma orientação masculina, que se encontra disfarçada de diferentes maneiras, como seu caráter abstrato, 
universal e imparcial. Esta orientação contamina seus ideais, sua argumentação, seus temas, sua metodologia e seus limites". E, porque não dizer, suas formas de avaliação!

Abaixo, cito algumas palavras dos próprios alunos na apreciação da matéria e da metodologia da avaliação:

\section{Alunas:}

"O que achei mais interessante no curso foi a manufatura do álbum, tendo em vista que além de um terapia, é uma forma interessante de aprender, já que vejo a aprendizagem sempre concomitante com alguma forma criativa, porque isso não deixa esquecer de várias situações do dia-a-dia, ou seja, o álbum foi uma forma de aprender brincando!"

"A manufatura do álbum fugiu da tradicional avaliação! Prefiro ver a criatividade, porque sou uma pessoa movida à paixão e tudo o que não possui amor profundo, me deixa totalmente sem reação, sem produtividade"

"O álbum nos levou a ter uma compreensão muito maior da disciplina"

"Fazer o álbum foi difícil, mas legal, pois voltei aos meus primeiros anos de educação".

“Aprendi muito mais com o álbum do que se fosse uma prova, pois no álbum tive que compreender e 'aplicar' o que aprendi e não apenas decorar, como fazemos na prova"

"A manufatura do álbum permite ao aluno ter uma nova experiência de pesquisa e de produção de novos conhecimentos"

\section{Alunos:}

"A manufatura do álbum aumenta a participação coletiva dos alunos"

"Pareceu-me coisa de pedagogia...mas gostei do álbum, porque foi diferente"

“Cara, o álbum foi um parto. Dificílimo. Na maior parte do tempo eu não tinha idéia do que eu estava fazendo, se estava fazendo certo... Sem falar que eu não tenho gosto de recortar e colar. No fim acho que ele acabou saindo melhor do que eu esperava. Mas não sei se faria de novo!"

Refletindo acerca da questão de gênero e a forma de avaliação, é interessante destacar a própria apreciação feita por um aluno de que, apesar de ter gostado de 
fazer o álbum, o mesmo era "coisa da pedagogia". Como se sabe (LOURO, 1994), a pedagogia e o magistério sofreram, desde o século passado, uma enorme feminização, sendo este campo um lugar privilegiado, aceito e prescrito socialmente para a realização profissional da mulher. Segundo Louro (1994), a pedagogia associou-se com a idéia de maternidade, como abdicação, amor, e cuidado, sendo uma saída para a realização daquelas "mães frustradas", as "solteironas" e "viúvas" que acabavam se dedicando a cuidar dos filhos dos outros. As habilidades de recorte, bem como de colagem, são aí quase sempre atribuídas ao sexo feminino (LOURO, 1997; LOURO, 1994). Nesse sentido, acreditamos que as palavras do aluno não foram apenas de associação da manufatura do álbum à pedagogia, mas ao próprio universo feminino, e este implicitado como algo pejorativo. Segundo Louro (1997, p. 61), desde criança "gestos, movimentos, sentidos são produzidos no espaço escolar e incorporados por meninos e meninas, tornando-se parte de seus corpos. Ali se aprende a olhar e a se olhar, se aprende a ouvir, a falar e a calar; se aprende a preferir. Todos os sentidos são treinados, fazendo com que cada um e cada uma conheça os sons, os cheiros e os sabores 'bons' e decentes e rejeite os indecentes; aprenda o que, a quem e como tocar (ou, na maior parte das vezes, não tocar); fazendo com que tenha algumas habilidades e não outras... E todas essas lições são atravessadas pelas diferenças, elas confirmam e também produzem diferença. Evidentemente, os sujeitos não são passivos receptores de imposições externas. Ativamente eles se envolvem e são envolvidos nessas aprendizagens- reagem, respondem, recusam ou as assumem inteiramente".

Pudemos perceber também, em muitos dos álbuns das alunas, uma abundância de imagens "femininas", como podemos ver no exemplo abaixo, quando a aluna 
Adriana Negrão tentou diferenciar o sofista que veria, na visão platônica, apenas as partes; e o filósofo, que teria a visão do todo.

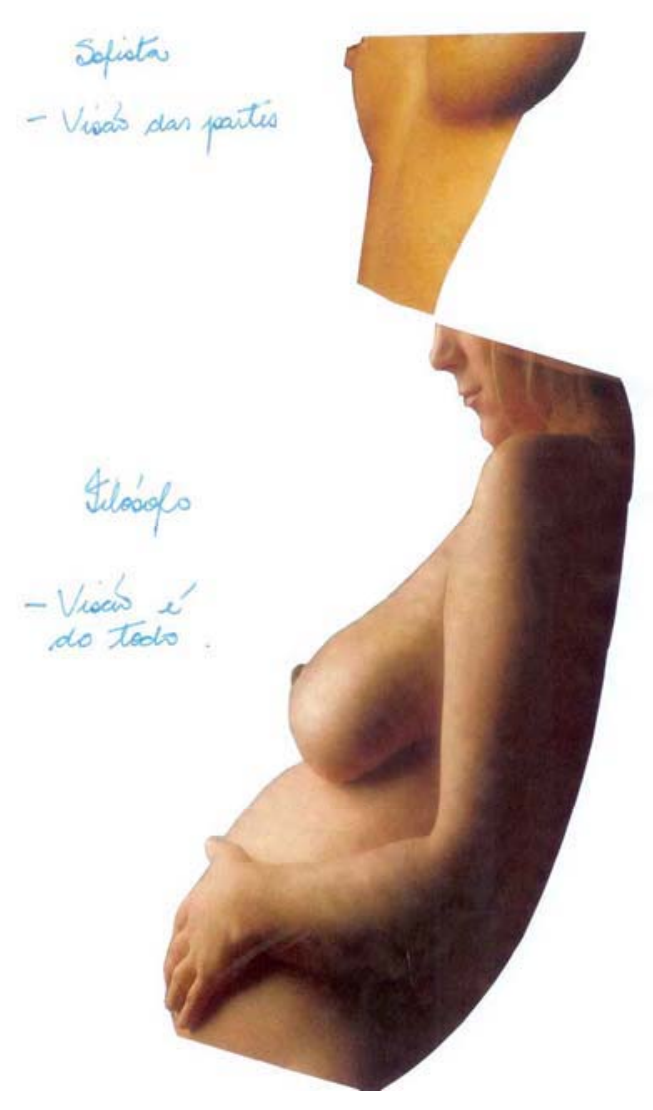

Ao ser perguntada sobre o porquê de ter escolhido aquela imagem, naquela parte de seu álbum, a aluna respondeu: "Pensei que a maternidade representa e aponta para algo além do que está ali mesmo. Você vê apenas a mulher, mas dentro dela tem um ser que vai além dela mesma... gostei muito dessa imagem, mas fiquei com muitas dúvidas se poderia e se deveria deixá-la aí mesmo".

A imagem é excelente! Mas, apesar disso, a aluna titubeia acerca de se deve ou não deixá-la em seu álbum. Perguntamo-nos aqui, seguindo a perspectiva que se abriu para nós de implicar o gênero de avaliação (o álbum) como algo que levou a uma certa avaliação do gênero, a seguinte questão de MacColl: "Na filosofia têm grande prestígio a metafísica, a lógica, a filosofia da ciência, a gnosiologia, a filosofia da mente, mas que atenção séria deu a filosofia a questões como a reprodução, a maternidade, o sexo?" (apud CERLETTI \& KOHAN, 1999, p. 29).

Se o papel que os filósofos desempenham na sociedade é a trilogia perplexidadepergunta-crítica, desnaturalizando o indiscutível (RICOEUR apud CERLETTI \& 
KOHAN, 1999, p.107), faz-se mister apontar a invisibilidade das questões relacionadas ao gênero na filosofia, não apenas no já tão acusado e suposto "sujeito neutro" (FARGANIS, 1997), mas nas próprias formas de avaliação que habitualmente utilizamos em nossos cursos. Em outras palavras, poderia afirmar que, no álbum, tive a intenção de buscar uma forma alternativa de avaliação, e acabei me deparando com novas habilidades avaliadas, não apenas as teórico-verbais, mas também a capacidade de transposição à práxis, bem como as próprias relações de gênero, tão esquecidas nos cursos de filosofia. Para mim, fica, portanto, a necessidade de lembrar sempre que a avaliação pode não ser apenas metodologia, mas também, e, sobretudo, uma eficaz política de gênero.

\section{Referência Bibliográfica}

CERLETTI, Alejandro. \& KOHAN, Walter Omar. O. A filosofia no ensino médio. Brasília: Editora Universidade de Brasília, 1999.

FARGANIS, Sondra. “O feminismo e a reconstrução da ciência social”. In Jaggar, AM. \& Bordo, S. Gênero, corpo, conhecimento. Rio de Janeiro: Record/Rosa dos tempos, 1997, pp.224-240.

LOURO, Guacira Lopes. Gênero, sexualidade e educação: uma perspectiva pósestruturalista. Petrópolis: Vozes, 1997.

LOURO, Guacira Lopes. "Mulheres na sala de aula". In Del Priore,M. (Org). História das Mulheres no Brasil. São Paulo: Contexto, 1994, pp. 443-481. 